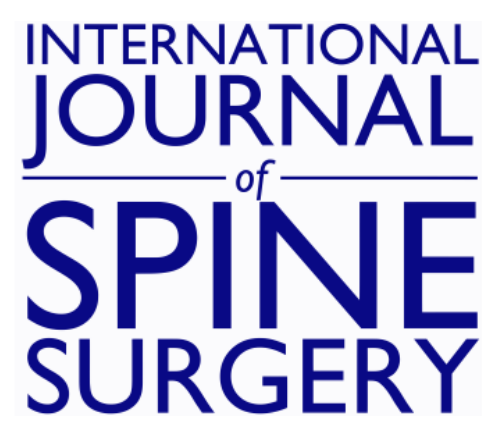

\title{
Two-Year Clinical and Radiographic Outcomes of Expandable Interbody Spacers Following Minimally Invasive Transforaminal Lumbar Interbody Fusion: A Prospective Study
}

CHOLL KIM, DAN S. COHEN, MARK D. SMITH, GARY A. DIX, INGRID Y. LUNA and GITA JOSHUA

Int J Spine Surg 2020, 14 (4) 518-526

doi: https://doi.org/10.14444/7068

http://ijssurgery.com/content/14/4/518

This information is current as of April 26, 2023.

Email Alerts Receive free email-alerts when new articles cite this article. Sign up at: http://ijssurgery.com/alerts 


\title{
Two-Year Clinical and Radiographic Outcomes of Expandable Interbody Spacers Following Minimally Invasive Transforaminal Lumbar Interbody Fusion: A Prospective Study
}

\author{
CHOLL KIM, MD, PHD, DAN S. COHEN, MD, MARK D. SMITH, MD, GARY A. DIX, MD, INGRID Y. \\ LUNA, MPH, GITA JOSHUA, MA \\ Globus Medical Inc, Audubon, Pennsylvania
}

\begin{abstract}
Background: The advantages of minimally invasive surgery for transforaminal lumbar interbody fusion (MIS TLIF) are well documented and include decreased blood loss, shorter length of hospital stay, and reduced perioperative costs. Clinical evidence for the use of expandable interbody spacers in conjunction with MIS TLIF, however, is scarce. This study sought to examine the clinical and radiographic outcomes of patients undergoing MIS TLIF with an expandable spacer.

Methods: Forty patients from 4 institutions who underwent MIS TLIF with an expandable spacer were included in this study and followed for 24 months. Investigator assessment of the surgical technique was reported. Patient selfreported outcomes included Visual Analog Scale (VAS), Oswestry Disability Index (ODI), and Short Form 36 (SF-36) physical and mental component scores. Disc height, foraminal height, segmental and lumbar lordosis, and fusion were also assessed.

Results: Investigators reported that intraoperative insertion, impaction, number of passes through the neural structures, and fit were better with an expandable spacer than a static spacer. Significant improvements in VAS, ODI, and SF-36 were reported as early as 6 weeks postoperatively and maintained through 24 months. Mean intervertebral and foraminal heights improved significantly from the preoperative time interval to as early as 6 weeks postoperatively and maintained through 24 months. There were no cases of spacer migration, subsidence, or collapse.

Conclusions: The use of an expandable interbody spacer in combination with MIS TLIF resulted in positive investigator assessments, immediate and progressive symptom relief, significant radiographic improvements, and no spacer-related complications.
\end{abstract}

Lumbar Spine

Keywords: expandable interbody spacer, TLIF, lumbar fusion, impaction, DDD

\section{INTRODUCTION}

Transforaminal lumbar interbody fusion (TLIF), a surgical option used to treat patients with disabling low back pain, is popular among spine surgeons because of its distinct advantages compared with alternative fusion approaches. In comparison with posterior lumbar interbody fusion, TLIF requires less nerve root retraction, which therefore may reduce injury and scarring. TLIF also circumvents the risks associated with anterior lumbar interbody fusion, such as vessel and sympathetic nerve injuries. Minimally invasive surgery (MIS) TLIF has gained momentum in recent years, and it has been associated with favorable short-term outcomes, such as decreased blood loss, ${ }^{1-5}$ decreased perioperative complications, ${ }^{2,3,6,7}$ shorter lengths of hospital stay, ${ }^{1-6,8}$ earlier rehabilitation, ${ }^{5}$ and consequently, reduced perioperative costs, ${ }^{7,9,10}$ in comparison with traditional open surgery. Long-term benefits of MIS TLIF have also been documented and include faster recovery and return to work ${ }^{1,4,6,7,11,12}$ and reduced 2-year cost. ${ }^{4}$

MIS TLIF is often used in conjunction with an interbody spacer to achieve bony fusion and neural decompression. Expandable interbody spacers have recently been introduced into the market and are available in different materials, footprints, and lordotic options. Expandable spacers have been 
Table 1. Study inclusion and exclusion criteria.

\section{Inclusion Criteria}

Objective evidence of degenerative disc disease at 1 or 2 contiguous levels between L2 and S1

Unresponsiveness to nonsurgical treatment for a minimum of $6 \mathrm{mo}$

Age at least $18 \mathrm{y}$, maximum $80 \mathrm{y}$

Ability to provide informed consent and return to all follow-up visits

Exclusion Criteria

More than 2 levels to be instrumented

Presence of systemic or localized infection at site of surgery

Previous fusion attempts at the involved level(s)

Spondylolisthesis unable to be reduced to grade 1

Presence of a disease entity that precludes possibility of bony fusion Immunosuppressive disorder

Pregnant, mentally incompetent, or a prisoner

Any known allergy to a metal alloy

designed to mitigate the challenges experienced with the use of traditional static interbody spacers, such as spacer migration, ${ }^{13}$ subsidence, ${ }^{14}$ breakage, retropulsion, ${ }^{15}$ and pseudoarthrosis. ${ }^{16}$ Because expandable spacers are inserted at a minimized profile, repeated trialing and impaction are not necessary, which decreases the risk of iatrogenic end plate damage. Furthermore, the spacer is expanded in situ, which allows for an optimized fit between vertebral end plates.

Although the success of MIS TLIF has been widely documented, adoption of the technique is technically difficult due to the nature of the surgical corridor. An expandable interbody spacer may facilitate insertion without placing the neural elements at risk. Clinical evidence of the efficacy of expandable spacers, however, is scarce. Therefore, the authors sought to examine the clinical and radiographic outcomes of patients undergoing MIS TLIF with an expandable interbody spacer. Outcomes examined included patient pain scores and satisfaction, surgeon assessment, restoration of intervertebral and foraminal height, and devicerelated complications.

\section{PATIENTS AND METHODS}

\section{Patients}

Four institutions participated in this investigation and obtained Institutional Review Board approval prior to study initiation. Consecutive patients undergoing MIS TLIF with the same expandable interbody spacer design were screened and asked to participate in the study if they met all of the inclusion criteria and none of the exclusion criteria (Table 1). A total of 40 consecutive patients consented and were enrolled and included in this analysis. Clinical and radiographic data were prospectively collected for each patient before surgery, and at 6 weeks, 3 months, 6 months, 12 months, and 24 months postoperatively.

\section{Surgical Technique}

Each patient was positioned prone, and lateral fluoroscopy was used to localize the operative level. The incision point was marked and made $4.5 \mathrm{~cm}$ lateral to midline. Simultaneous anteroposterior and lateral fluoroscopy were used to insert Jamshidi needles into the pedicles and to place k-wires through the pedicles. Sequential dilation was used to place a $22-\mathrm{mm}$ diameter tubular retractor down to the facet on the more symptomatic side.

Under microscopic magnification and illumination, the superior and inferior facets were resected with a drill. Bone shavings were collected to be used in the interbody fusion. The ligamentum flavum was removed, and the traversing and exiting nerve roots were identified. A thorough discectomy was performed, and the disc space was dilated with expandable trials.

Interbody fusion was performed with locally harvested autograft and bone graft extenders. Once the disk space was filled with graft material, the appropriately sized collapsed cage was implanted under fluoroscopy and expanded to the desired height.

Supplemental fixation was achieved with transpedicular screws and rods. If necessary, compression was performed across the posterior fixation before the wound was closed.

\section{Outcome Measures}

Demographic and operative data collected included patient age, sex, operative level, fluoroscopic and operative times, estimated blood loss, and length of hospital stay. Initial insertion and final expansion spacer heights were recorded. Investigators were asked to assess their surgical experience with the use of the expandable spacer by evaluating (1) ease of spacer insertion (easier, same, or worse than with a static spacer); (2) extent of spacer impaction (none, less than, same as, or more than with a static spacer); (3) number of instrumental passes through the neural structure (less, same, or more than with a static spacer); and (4) optimal fit achieved by the spacer (worse, same, or better than with a static spacer). Patient self-reported outcomes were collected preoperatively and at each follow-up 
Table 2. Summary of operative data (mean \pm SD).

\begin{tabular}{lcc}
\hline & Single-Level & 2-Level \\
\hline Fluoroscopic time, s & $54.7 \pm 38.7$ & $91.7 \pm 98.7$ \\
Operative time, min & $149.7 \pm 77.0$ & $320.4 \pm 112.7$ \\
Blood loss, cc & $63.8 \pm 50.3$ & $233.3 \pm 116.9$ \\
Hospital stay, d & $1.9 \pm 0.8$ & $2.7 \pm 0.8$ \\
\hline
\end{tabular}

visit, and they included Visual Analog Scale (VAS) scores to assess lower back, left leg, and right leg pain; Oswestry Disability Index (ODI) to measure functional disability; and the Short-Form 36 (SF36) to evaluate physical and mental quality of life.

Patient radiographs (anteroposterior and lateral) were collected before surgery and at each follow-up visit to assess intervertebral and foraminal heights, segmental and lumbar lordosis, and any devicerelated complications. Intervertebral disc height was measured at the middle of the end plates immediately above and below the referenced index levels on the lateral plane. Foraminal height was measured as the distance from the inferior pedicle wall of the level above to the superior pedicle wall of the level below. Segmental lordosis was measured from the superior end plate of the cephalad vertebral body to the inferior end plate of the caudal vertebral body, whereas lumbar lordosis was measured from the superior end plate of $\mathrm{L} 1$ to the superior end plate of S1. Computed tomography (CT) scans were taken at 12 months postoperatively to assess bony fusion, which was defined as the presence of bridging trabecular bone formation across the intervertebral space. Implant subsidence was defined as a loss of intervertebral disc height greater than $2 \mathrm{~mm}$ in comparison with 6-week postoperative measurements on radiographs.

\section{Statistical Analysis}

Statistical analysis was performed with SPSS v20.0.0 software for Windows (IBM Corp, Armonk, New York). Changes in VAS, ODI, and SF-36 scores from before surgery to each follow-up time interval were assessed using the Wilcoxon signedrank test for ordinal variables. Furthermore, changes in intervertebral and foraminal heights, and segmental and lumbar lordosis from preoperative to all follow-up intervals were assessed using the paired-sample $t$ test. Finally, differences in surgical technique assessment between operative levels were determined using the $\chi^{2}$ test. Statistical significance was indicated at $P<.05$.

\section{RESULTS}

\section{Demographic and Operative Data}

This study comprised 40 patients who underwent MIS TLIF with expandable interbody spacers. Mean patient age was $53.6 \pm 12.7$ years, and $72.5 \%$ (29 of 40 ) of patients were female. Indications for surgery included low back pain $(90.2 \%)$, leg pain $(76.5 \%)$, buttock pain $(5.9 \%)$, hip pain $(3.9 \%)$, weakness $(2.0 \%)$, muscle spasms $(2.0 \%)$, and groin pain $(2.0 \%)$, with many patients reporting more than 1 indication. A total of 33 patients underwent single-level TLIF, whereas 7 patients had a 2-level procedure. Surgery was most common at L4 to L5 $(57.5 \%)$ in the single-level group, and at L4 to $\mathrm{S} 1(85.7 \%)$ in the 2-level group. The mean initial insertion height of the spacers used in this study was $9.7 \pm 1.9 \mathrm{~mm}$; mean disc height achieved by expandable spacers was $13.5 \pm 2.5 \mathrm{~mm}$, representing a $38.5 \%$ increase. No intraoperative complications were reported. Surgical details are summarized in Table 2.

\section{Surgical Technique Assessment}

Investigators were asked to assess their experience with the use of an expandable spacer in comparison with their previous experience using a static spacer. Surgeons reported that insertion with an expandable spacer was easier than with a static spacer for $90 \%$ of the surgeries performed in this study; insertion of an expandable spacer was the same as a static cage in $10 \%$ of cases. Expandable spacer impaction was reported to be less than a static spacer in $77.5 \%$ of cases, and the same as a static spacer in $10 \%$ of cases. Surgeons reported no impaction for the remaining cases $(12.5 \%)$. Surgeons also reported that the number of instrumental passes through the neural structure was less with an expandable spacer than with a static spacer in $70 \%$ of cases and the same as a static spacer in $30 \%$ of cases. Finally, surgeons felt that an optimal fit achieved by an expandable spacer was better than a static spacer in $100 \%$ of the surgeries performed. The surgical technique assessment was also studied by operative level (L4-L5 versus L5-S1; Table 3). For procedures performed at the L5 to S1 level, surgeons reported easier insertion, less impaction, and fewer instrumental passes through the neural structure with an expandable spacer compared with a static spacer in $85 \%, 78 \%$, and $71 \%$ of cases, respectively. 
Table 3. Surgical technique assessment.

\begin{tabular}{lcc}
\hline & \multicolumn{2}{c}{ Operative Level } \\
\cline { 2 - 3 } Criterion & L4-L5 & L5-S1 \\
\hline Ease of expandable spacer insertion, \% & & \\
Easier than static spacer & 94.7 & 85.7 \\
Same as static spacer & 5.3 & 14.3 \\
Worse than static spacer & 0 & 0 \\
Extent of expandable spacer impaction, $\%$ & & 7.1 \\
None & 15.8 & 78.6 \\
Less than static spacer & 73.7 & 14.3 \\
Same as static spacer & 10.5 & \\
Number of instrumental passes through neural structure with & \\
expandable spacer, \% & 63.2 & 71.4 \\
Less than static spacer & 36.8 & 28.6 \\
Same as static spacer & 0 & 0 \\
More than static spacer & $\%$ & 100 \\
Optimal fit achieved by expandable spacer, $\%$ & 0 \\
Better than static spacer & 100 & 0 \\
Same as static spacer & 0 & \\
Worse than static spacer & 0 &
\end{tabular}

\section{Self-Reported Outcomes}

Overall, patients reported decreased pain and disability, and improved physical and mental health, as early as 6 weeks postoperatively maintained through 24 months. Mean lower back, left leg, and right leg pain VAS scores decreased significantly from preoperative to each postoperative time interval (Table 4). Lower back pain decreased by $31.9 \%$ by 6 weeks postoperatively, and by $59.1 \%$ by 24 months postoperatively, compared with the preoperative time interval. Left leg pain scores also decreased by $53.3 \%$ by 6 weeks and by $72.4 \%$ by 24 months; similarly, right leg pain scores decreased by $52.7 \%$ by 6 weeks and by $73.1 \%$ by 24 months. ODI scores also decreased significantly from preoperative time point
Table 4. Average Visual Analog Scale (VAS) scores (mean $\pm \mathrm{SD}$ ).

\begin{tabular}{lccc}
\hline & $\begin{array}{c}\text { VAS Low } \\
\text { Back Pain }\end{array}$ & $\begin{array}{c}\text { VAS Left } \\
\text { Leg Pain }\end{array}$ & $\begin{array}{c}\text { VAS Right } \\
\text { Leg Pain }\end{array}$ \\
\hline Preoperative & $57.9 \pm 27.6$ & $32.3 \pm 31.9$ & $33.4 \pm 33.5$ \\
$6 \mathrm{wk}$ & $39.4 \pm 31.5$ & $15.1 \pm 26.5$ & $15.8 \pm 26.9$ \\
$3 \mathrm{mo}$ & $26.5 \pm 23.3$ & $7.1 \pm 17.9$ & $15.5 \pm 23.9$ \\
$6 \mathrm{mo}$ & $24.6 \pm 25.8$ & $11.5 \pm 21.9$ & $19.9 \pm 30.4$ \\
$12 \mathrm{mo}$ & $22.9 \pm 28.2$ & $10.6 \pm 20.8$ & $10.2 \pm 21.2$ \\
$24 \mathrm{mo}$ & $23.7 \pm 28.1$ & $8.9 \pm 17.8$ & $9.0 \pm 19.7$ \\
$P$ value & $<.001$ & $<.001$ & $<.001$ \\
\hline
\end{tabular}

to each postoperative time interval, as early as 6 weeks postoperatively $(P<.001$; Figure 1$)$; disability scores decreased by $24.8 \%$ at 6 weeks' and by $59.7 \%$ at 24 months' postoperative follow-up. SF-36 physical and mental component scores increased significantly from the preoperative time point to as early as 6 weeks' postoperative follow-up, and increases were maintained through 24-month follow-up $(P<.001$; Figure 2). Physical component scores increased by $16.3 \%$ at 6 -week and by $47.4 \%$ at 24 -month followup; mental component scores increased by $11.4 \%$ at 6-week and by $12.4 \%$ at $24-$ month follow-up.

\section{Radiographic Outcomes and Complications}

Mean intervertebral disc height increased significantly from $7.3 \pm 2.6 \mathrm{~mm}$ before surgery to $12.5 \pm$ $1.2 \mathrm{~mm}$ at 24 months postoperatively $(P<.001)$; this represents a $71.2 \%$ increase. Similarly, foraminal height increased significantly from $17.3 \pm 4.3$ $\mathrm{mm}$ before surgery to $19.4 \pm 4.2 \mathrm{~mm}$ at 24 months postoperatively $(P<.001$; Figure 3$)$, representing a $12.1 \%$ increase. Neither segmental nor lumbar lordosis changed significantly from before surgery

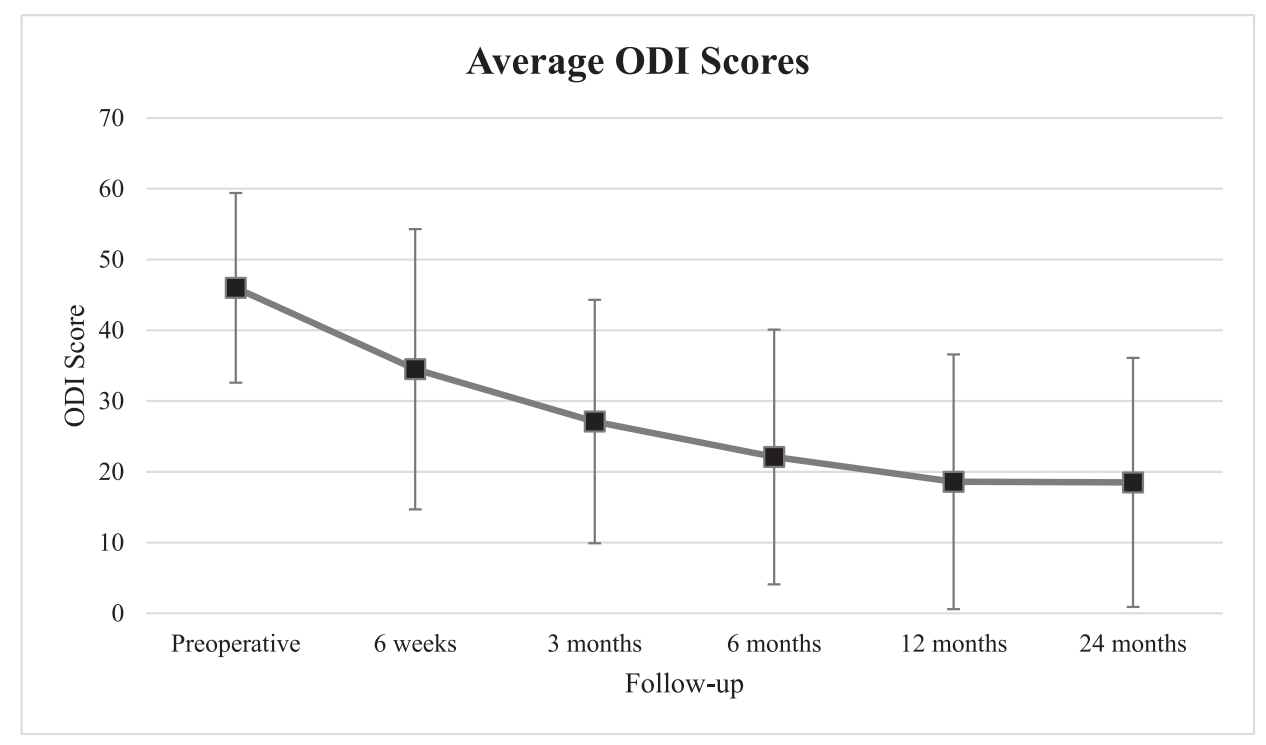

Figure 1. Average Oswestry Disability Index (ODI) scores. 


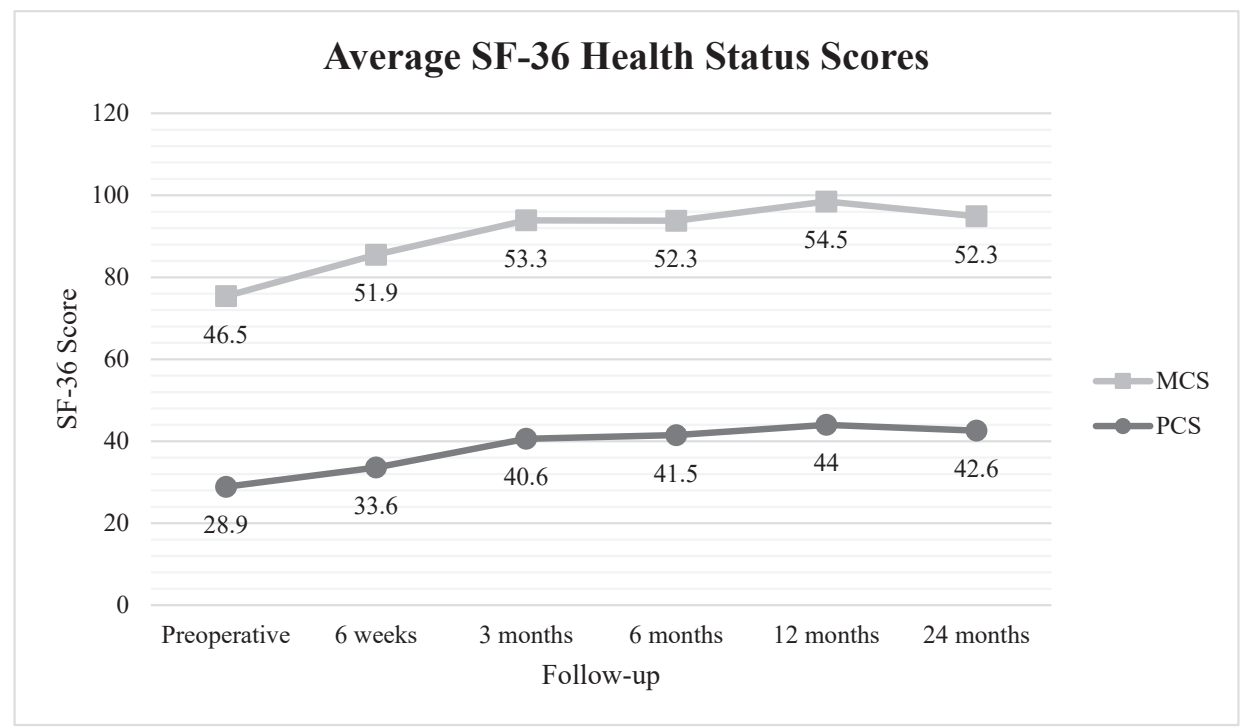

Figure 2. Average Short Form 36 (SF-36) health status scores.

to any postoperative time interval. All patients achieved bony fusion by 24 months postoperatively (Figure 4). No cases of spacer migration, breakage, or subsidence were reported. There were no other complications or neurologic injuries reported.

\section{DISCUSSION}

MIS TLIF has become increasingly popular in recent years because of its perceived perioperative and long-term advantages, including decreased blood loss and complications, shorter hospital stays, earlier rehabilitation, decreased costs, and faster return to work in comparison with traditional open
TLIF. $^{1-12}$ Although interbody spacers have been used to increase the likelihood of solid bony fusion between vertebral bodies, studies reporting the short- and long-term outcomes of expandable interbody spacers with MIS TLIF are few. This study sought to examine the clinical and radiographic outcomes of patients undergoing MIS TLIF using expandable technology. Patients experienced immediate improvement in pain and disability, significant increases in disc and foraminal height, and high fusion rates by 2-year follow-up.

Using a survey of surgeon perceptions comparing static versus expandable spacers, surgeons agreed that the expandable spacer made insertion easier,

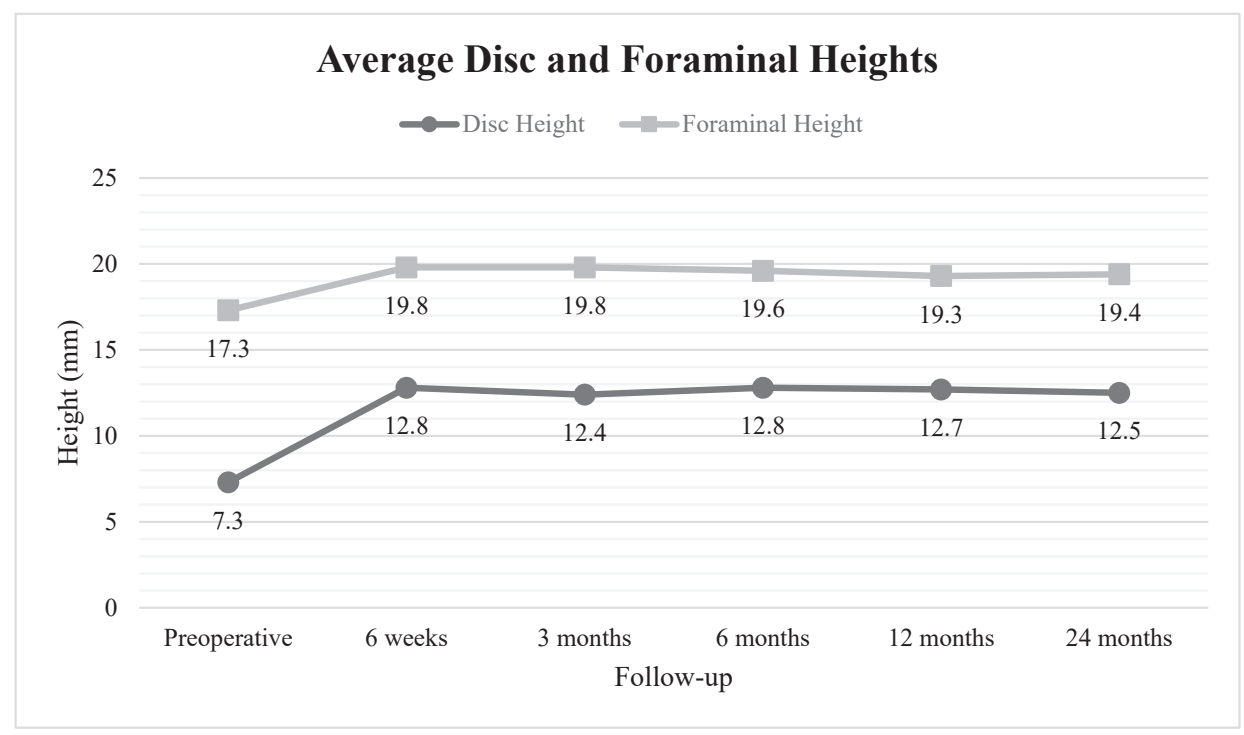

Figure 3. Average disc and foraminal heights. 

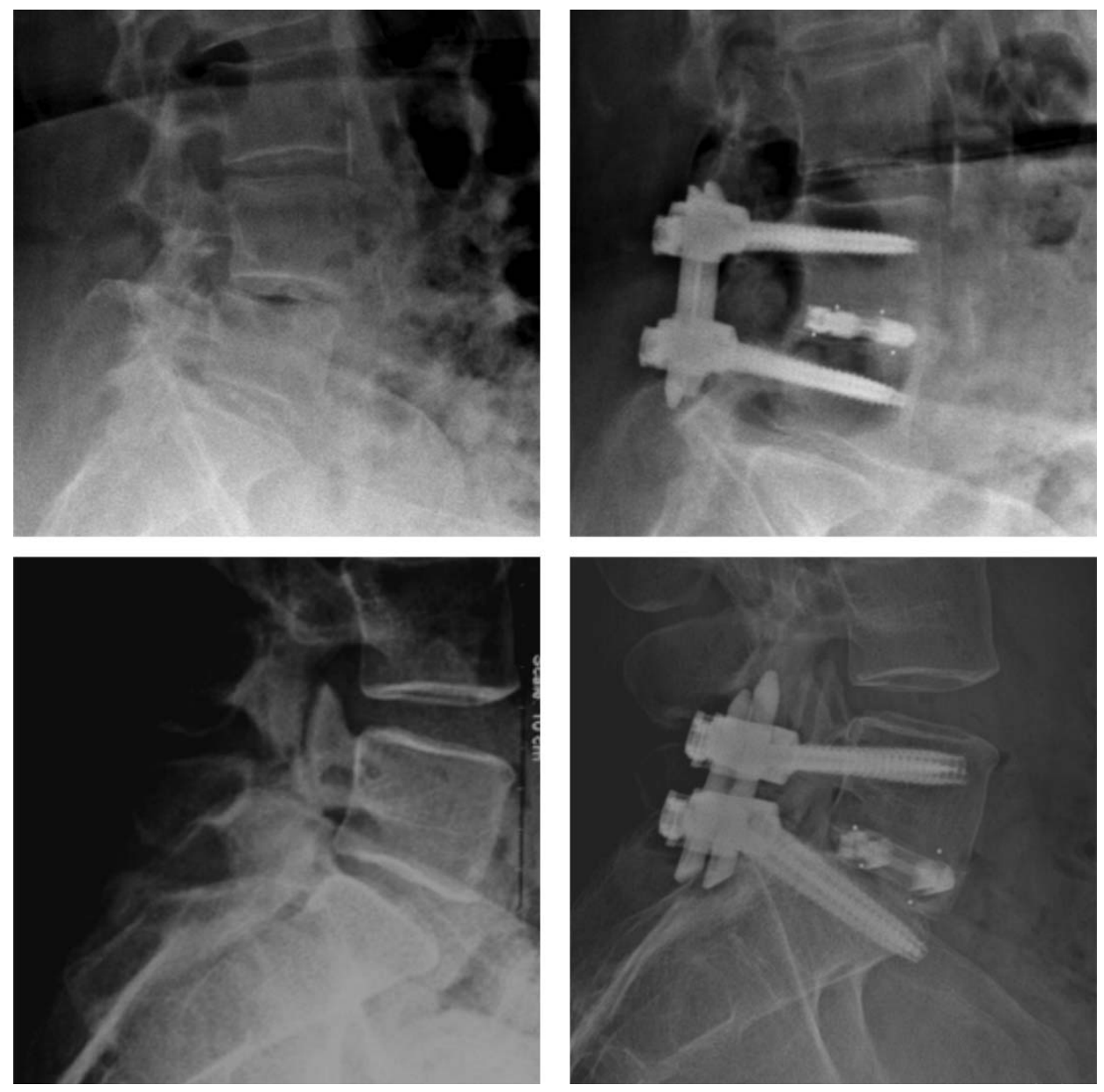

Figure 4. Bony fusions 24 months postoperative.

required less impaction and fewer instrumental passes near the neural elements, and provided an optimal fit when compared to a static spacer. Expandable spacers have greater ease of insertion and implantation, likely due to their reduced profile during insertion and subsequent expansion in situ. This feature may facilitate safer insertion and decreased manipulation of - and risk to-neural elements. Both McAfee et $\mathrm{al}^{17}$ and Klinger et $\mathrm{al}^{18}$ reported cases of incidental durotomies after static cage insertion and nerve root decompression during TLIF procedures. Elias et $\mathrm{al}^{19}$ reported a high incidence of radiculopathy following static spacer insertion. Further, Rihn et $\mathrm{al}^{20}$ reported several occurrences of postoperative radiculitis following spacer implantation. This study found no dural injuries or nerve root irritation, suggesting that an expandable spacer is successful in minimizing these risks postoperatively.

MIS TLIF was performed at L5 to S1 in 20 of 47 operative levels in this study. The wedge shape of the L5 to S1 disc space makes it an especially challenging operative level. Choi et $\mathrm{al}^{21}$ described their technique to overcome injury of the neural elements during MIS TLIF with spacers. To enlarge the posterior disc space, the posterior edges of the caudal end plates of L5 were removed, and if necessary, the cranial end plates of S1 were also removed; the lower portion of the L5 transverse process and the upper portion of $\mathrm{S} 1$ were also resected in some instances. This allowed adequate space for insertion of a static spacer. When considering the L5 to S1 disc space independently, the investigators in this study ${ }^{21}$ reported insertion of an expandable spacer to be easier than insertion of a static spacer $85 \%$ of the time, and spacer fit being optimal $100 \%$ of the time. An expandable spacer may allow easy insertion and optimal fit in comparison with a static spacer in difficult operative levels without the added steps of widening the posterior disc space.

Based on self-reported outcomes, patients in this study reported immediate and progressive symptom relief after MIS TLIF with an expandable spacer. 
Although there were significant improvements in patient-reported pain, disability, and physical and mental well-being, the greatest improvements were reported for right and left leg pain. By 6 weeks postoperatively, right and left leg pain scores decreased by more than $50 \%$, and this improvement progressed to more than $70 \%$ pain relief by 24 months postoperatively. Similar improvements in patient pain and disability after use of an expandable spacer have been reported in the literature, ${ }^{22-29}$ with patient samples ranging from 25 to 470, and follow-up ranging from 3 months to 4 years postoperatively. Furthermore, when comparing expandable to static spacer groups, Hawasli et $\mathrm{al}^{30}$ found a significantly lower mean ODI score in the expandable group; Kale et $\mathrm{al}^{31}$ also reported a significant decrease in VAS low back pain in patients treated with an expandable spacer in comparison with patients treated with simple discectomy. There is strong evidence to suggest that the use of an expandable spacer provides excellent and immediate clinical improvement, potentially greater than that experienced with a static interbody spacer.

Spacer collapse is a potential concern with the use of expandable spacers. ${ }^{32}$ Patients in this study experienced a greater than $70 \%$ increase in intervertebral disc height at 6 weeks postoperatively compared with the preoperative time interval, and a greater than $70 \%$ increase was maintained at 24 months postoperatively. To date, only 1 study has compared disc height changes between static and expandable spacers. ${ }^{30}$ The authors reported a significantly larger and longer-lasting increase in disc height with an expandable spacer compared with a static spacer.

Although the data on expandable spacers and spacer collapse are limited, there are positive trends demonstrating the stability of expandable spacers. Subsidence of an expandable spacer is another concern among spine surgeons. ${ }^{22}$ Overdistraction of the disc space, in addition to the use of narrow spacers and lack of supplemental fixation, ${ }^{32-34}$ are thought to be risk factors associated with spacer subsidence. A biomechanical study ${ }^{35}$ examining vertebral body end plate strength between static and expandable spacers found that the repeated trialing necessary for a static spacer increases the likelihood of postoperative subsidence. Because an expandable spacer requires less impaction than a static spacer, the risk of iatrogenic end plate damage is reduced, thereby minimizing the risk of postoperative subsidence. Subsidence is further prevented by achieving optimal spacer fit, facilitated by controlled expansion and tactile feedback of the expandable spacer examined in this study.

One limitation of this study is the lack of a static comparison group as a control, which would allow for direct comparison of outcomes between the spacers. Furthermore, although this study followed patients for 2 years postoperatively, longer followup and a greater number of patients are necessary to determine the long-term outcomes - such as revision surgery and adjacent segment disease-associated with the use of expandable technology. This study is strengthened by its prospective and multicenter design because the investigators were able to screen and enroll consecutive patients in this study, collecting data on the same outcome measures at the same time intervals. This multicenter, consecutively enrolled patient design strengthens the representativeness of the study patients, although whether this population is representative is unknown. More studies on similar implant designs and techniques may allow for greater generalizability of the conclusions of this research.

\section{CONCLUSION}

Although MIS TLIF may be technically challenging, use of expandable spacers led to positive surgical assessment, immediate and progressive symptom relief, and significant improvements in disc and foraminal height restoration. No neurologic injuries or spacer-related complications were reported.

\section{REFERENCES}

1. Lee LY, Idris Z, Beng TB, et al. Outcomes of minimally invasive surgery compared to open posterior lumbar instrumentation and fusion. Asian J Neurosurg. 2017;12(4):620-637.

2. Khan NR, Clark AJ, Lee SL, Venable GT, Rossi NB, Foley KT. Surgical outcomes for minimally invasive vs open transforaminal lumbar interbody fusion: an updated systematic review and meta-analysis. Neurosurgery. 2015;77(6):847-874.

3. Price JP, Dawson JM, Schwender JD, Schellhas KP. Clinical and radiologic comparison of minimally invasive surgery with traditional open transforaminal lumbar interbody fusion: a review of 452 patients from a single center. Clin Spine Surg. 2018;31(2):E121-E126.

4. Parker SL, Mendenhall SK, Shau DN, et al. Minimally invasive versus open transforaminal lumbar interbody fusion for degenerative spondylolisthesis: comparative effectiveness and cost-utility analysis. World Neurosurg. 2014;82(1):230-238.

5. Seng C, Siddiqui MA, Wong KP, et al. Five-year 
outcomes of minimally invasive versus open transforaminal lumbar interbody fusion: a matched-pair comparison study. Spine. 2013;38(23):2049-2055.

6. Virdee JS, Nadig A, Anagnostopoulos G, George KJ. Comparison of peri-operative and 12-month lifestyle outcomes in minimally invasive transforaminal lumbar interbody fusion versus conventional lumbar fusion. $B r \quad J$ Neurosurg. 2017;31(2):167-171.

7. Cheng JS, Park P, Le H, Reisner L, Chou D, Mummaneni PV. Short-term and long-term outcomes of minimally invasive and open transforaminal lumbar interbody fusions: is there a difference? Neurosurg Focus. 2013;35(2):E6.

8. Serban D, Calina N, Tender G. Standard versus minimally invasive transforaminal lumbar interbody fusion: a prospective randomized study. Biomed Res Int. 2017;2017:7236970.

9. Phan K, Hogan JA, Mobbs RJ. Cost-utility of minimally invasive versus open transforaminal lumbar interbody fusion: systematic review and economic evaluation. Eur Spine $J$ 2015;24(11):2503-2513.

10. Sulaiman WA, Singh M. Minimally invasive versus open transforaminal lumbar interbody fusion for degenerative spondylolisthesis grades 1-2: patient-reported clinical outcomes and cost-utility analysis. Ochsner J. 2014;14(1):32-37.

11. Djurasovic M, Rouben DP, Glassman SD, Casnellie MT, Carreon LY. Clinical outcomes of minimally invasive versus open TLIF: a propensity-matched cohort study. $A m J$ Orthop (Belle Mead NJ). 2016;45(3):E77-E82.

12. Kim JS, Jung B, Lee SH. Instrumented minimally invasive spinal-transforaminal lumbar interbody fusion (MISTLIF); minimum 5-years follow-up with clinical and radiologic outcomes. Clin Spine Surg, 2018;31(6):E302-E309.

13. Chen L, Yang $\mathrm{H}$, Tang $\mathrm{T}$. Cage migration in spondylolisthesis treated with posterior lumbar interbody fusion using BAK cages. Spine (Phila Pa 1976). 2005;30(19):2171-2175.

14. Kim MC, Chung HT, Cho JL, Kim DJ, Chung NS. Subsidence of polyetheretherketone cage after minimally invasive transforaminal lumbar interbody fusion. $J$ Spinal Disord Tech. 2013;26(2):87-92.

15. Kimura H, Shikata J, Odate S, Soeda T, Yamamura S. Risk factors for cage retropulsion after posterior lumbar interbody fusion: analysis of 1070 cases. Spine (Phila $\mathrm{Pa}$ 1976). 2012;37(13):1164-1169.

16. Aoki Y, Yamagata M, Nakajima F, et al. Examining risk factors for posterior migration of fusion cages following transforaminal lumbar interbody fusion: a possible limitation of unilateral pedicle screw fixation. $J$ Neurosurg Spine 2010;13(3):381-387.

17. McAfee PC, DeVine JG, Chaput CD, et al. The indications for interbody fusion cages in the treatment of spondylolisthesis: analysis of 120 cases. Spine (Phila Pa 1976) 2005;30(6 suppl):S60-S65.

18. Klingler JH, Volz F, Krüger MT, et al. Accidental durotomy in minimally invasive transforaminal lumbar interbody fusion: frequency, risk factors, and management. Sci World J. 2015;2015:1-7.

19. Elias WJ, Simmons NE, Kaptain GJ, Chadduck JB, Whitehill R. Complications of posterior lumbar interbody fusion when using a titanium threaded cage device. $J$ Neurosurg Spine. 2000;93(1 suppl):45-52.
20. Rihn JA, Patel R, Makda J, et al. Complications associated with single-level transforaminal lumbar interbody fusion. Spine J. 2009;9(8):623-629.

21. Choi WS, Kim JS, Hur JW, Seong JH. Minimally invasive transforaminal lumbar interbody fusion using bananashaped and straight cages: radiological and clinical results from a prospective randomized clinical trial. Neurosurgery. 2018;82(3):289-298.

22. Alimi M, Shin B, Macielak M, et al. Expandable polyaryl-ether-ether-ketone spacers for interbody distraction in the lumbar spine. Global Spine J. 2015;5(3):169-178.

23. Kim CW, Doerr TM, Luna IY, et al. Minimally invasive transforaminal lumbar interbody fusion using expandable technology: a clinical and radiographic analysis of 50 patients. World Neurosurg. 2016;90:228-235.

24. Barrett-Tuck R, Del Monaco D, Block JE. One and two level posterior lumbar interbody fusion (PLIF) using an expandable, stand-alone, interbody fusion device: a VariLift ${ }^{\circledR}$ case series. J Spine Surg. 2017;3(1):9-15.

25. Coe JD, Zucherman JF, Kucharzyk DW, Poelstra KA, Miller LE, Kunwar S. Multiexpandable cage for minimally invasive posterior lumbar interbody fusion. Med Devices (Auckl). 2016;9:341-347.

26. Kim JW, Park HC, Yoon SH, et al. A multi-center clinical study of posterior lumbar interbody fusion with the expandable stand-alone cage (tyche ${ }^{\circledR}$ cage) for degenerative lumbar spinal disorders. $J$ Korean Neurosurg Soc. 2007;42(4):251-257.

27. Neely WF, Fichtel F, del Monaco DC, Block JE. Treatment of symptomatic lumbar disc degeneration with the VariLift-L interbody fusion system: retrospective review of 470 cases. Int J Spine Surg. 2016;10:15.

28. Park JH, Bae CW, Jeon SR, Rhim SC, Kim CJ, Roh SW. Clinical and radiological outcomes of unilateral facetectomy and interbody fusion using expandable cages for lumbosacral foraminal stenosis. $J$ Korean Neurosurg Soc. 2010;48(6):496-500.

29. Wang MY. Improvement of sagittal balance and lumbar lordosis following less invasive adult spinal deformity surgery with expandable cages and percutaneous instrumentation. $J$ Neurosurg Spine. 2013;18(1):4-12.

30. Hawasli AH, Khalifeh JM, Chatrath A, Yarbrough CK, Ray WZ. Minimally invasive transforaminal lumbar interbody fusion with expandable versus static interbody devices: radiographic assessment of sagittal segmental and pelvic parameters. Neurosurg Focus. 2017;43(2):E10.

31. Kale A, Oz II, Onk A, Kalaycı M, Büyükuysal Ç. Unilaterally posterior lumbar interbody fusion with double expandable peek cages without pedicle screw support for lumbar disc herniation. Neurol Neurochir Pol. 2017;51(1):53-59.

32. Gonzalez-Blohm SA, Doulgeris JJ, Aghayev K, et al. In vitro evaluation of a lateral expandable cage and its comparison with a static device for lumbar interbody fusion: a biomechanical investigation. J Neurosurg Spine. 2014;20(4):387-395.

33. Lee DY, Jeong ST, Hong CH, Choi YL, Kang BH, Kim DH. Risk factors of cage subsidence after posterior lumbar interbody fusion. J Korean Neurosurg Soc. 2016;23(2):100-107.

34. Tohmeh AG, Khorsand D, Watson B, Zielinski X. Radiographical and clinical evaluation of extreme lateral interbody fusion: effects of cage size and instrumentation type 
with a minimum of 1-year follow-up. Spine (Phila Pa 1976). 2014;39(26):E1582-E1591.

35. Kwon AJ, Hunter WD, Moldavsky M, Salloum K, Bucklen B. Indirect decompression and vertebral body endplate strength after lateral interbody spacer impaction: cadaveric and foam-block models. J Neurosurg Spine. 2016;24(5):727-733.

Disclosures and COI: Dr Kim has nothing to disclose. Drs Cohen, Smith, and Dix are consultants for and receive royalties and consulting fees from a company involved in the manufacture of a device examined in this study. Ms Luna is a former salaried employee of a company involved in the manufacture of a device examined in this study. Ms Joshua is a salaried employee of a company involved in the manufacture of a device examined in this study. All authors approved the final manuscript for submission for publication.

Corresponding Author: Gita Joshua, MA, Globus Medical Inc, 2560 General Armistead Ave, Audubon, PA. Phone: (610) 930-1800; Email: gjoshua@globusmedical.com.

Published 28 August 2020

This manuscript is generously published free of charge by ISASS, the International Society for the Advancement of Spine Surgery. Copyright (c) 2020 ISASS. To see more or order reprints or permissions, see http://ijssurgery.com. 